\title{
Research on Prehistoric Hats in Xinjiang (2000 BC-200 BC)
}

\author{
Xiaoyu $\mathrm{Xin}^{1}$ \\ ${ }^{1}$ College of Fashion \& Art Design, Donghua University, Shanghai, China \\ Correspondence: Xiaoyu Xin, Donghua University, No.1882, West Yan'an Road, Changning District, 200051 \\ Shanghai, China. Tel: 86-186-9027-2006. E-mail: xxy1314@sina.cn
}

Received: January 26, 2015 Accepted: February 6, 2015 Online Published: March 27, 2015

doi:10.5539/ass.v11n7p333

URL: http://dx.doi.org/10.5539/ass.v11n7p333

\begin{abstract}
Based on archaeological evidence, this paper analyzes hats unearthed from prehistoric Xinjiang. Three typical categories of ancient hats can be recognized according to different styles and structures. And each of them represents the local dressing culture of different geographical areas of Xinjiang. Meanwhile, the similarities between prehistoric hats from Xinjiang and other Ancient tombs in Eurasia indicate early cultural communications between different civilizations from the Bronze Age to the early Iron Age.
\end{abstract}

Keywords: prehistoric, hats, Xinjiang

\section{Introduction}

Located in the hinterland of Eurasia, Xinjiang, in Northwest China, has been at the intersection of eastern and western civilizations since ancient times. In recent years, a large number of corpses unearthed from Tarim Basin have provided an opportunity for the study of Xinjiang's prehistoric civilization. Hats played an important role in the lives of ancient inhabitants of Xinjiang, for practical functions, such as shielding and insulation and for deep-rooted spiritual reasons. Scholars have done some primary research on ancient hats from Xinjiang. For instance, $\mathrm{Wu}$ Yanchun discusses the high-peaked headgear culture in the West region of Ancient China (Yanchun \& Libo, 2004, pp. 60-68) while Barber believes that there is a certain link between high-pointed hats unearthed from the Turfan area and witches (Barber, 1999, p. 200) And Karlene considers that the pointed hats in prehistoric Xinjiang have a certain ritualistic origin (Karlene, 2010, pp. 92-98). It is thus clear that the study of prehistoric hats of Xinjiang is of significant academic value. The early headgear culture not only unveils the lifestyle of prehistoric Xinjiang, but various bird-shaped or animal-shaped hats may be important symbols of different primitive ethnic groups.

Prehistoric hats unearthed from Xinjiang that are of such a wide variety, in large quantities, and in various unique forms and styles, are rare worldwide. According to released materials, there are over 120 prehistoric hats unearthed from Xinjiang in total, in areas with differing cultures, dating back from the Bronze Age in $2000 \mathrm{BC}$ to the early Iron Age around the time of the beginning of Han Dynasty, mainly distributed in the Eastern area of Mount Tianshan and the vast hinterland of Tarim Basin. These include felt hats, fur hats, woolen cloth hats, wool knitting hats, hairnets and high-peaked hats.

\section{Archeological Hats from Prehistoric Xinjiang}

Prehistoric hats from Xinjiang can be generally divided into three categories: earflap hats, straight-edge hats and high-peaked hats. Earflap hats are fitted and light, with earflaps on both sides to shield wearers' cheeks and ears, characterized by strong protection and cold-proof functions; straight-edge hats feature straight edges and pointed or domed peaks without earflaps, but have a variety of shapes and certain practical functions. High-peaked hats feature higher and more exaggerated shapes, which are distinct spiritual indicators.

\subsection{Earflap Hats}

Earflap hats with two pieces of earflaps on both sides have been unearthed from multiple graves. Their sound protection and convenience resulted in their popularity in prehistoric Xinjiang. They have pointed or domed peaks, angular or lune earflaps on both sides with chin-cords for fastening below wearers' jaws to protect their ears and cheeks. Earflap hats are usually made of felt, woolen cloth and fur, and were used in autumn or winter to protect against the cold climate in prehistoric Xinjiang. 

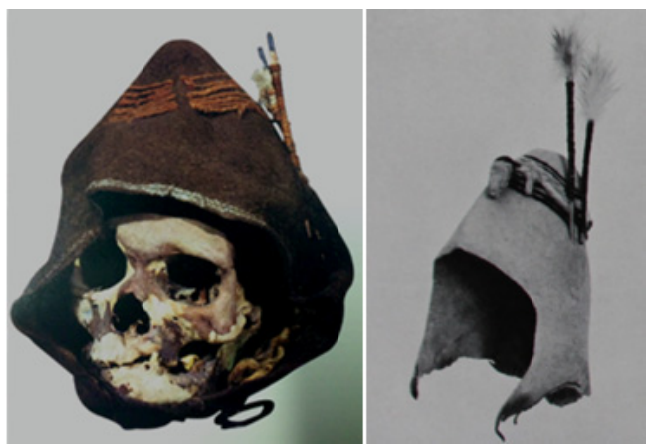

Figure 1. One-piece peaked hats.

(Gumugou Cemetery \& Qum Darya Grave36)

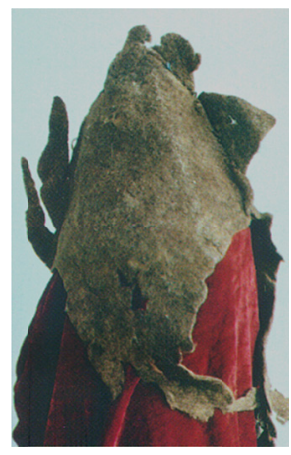

Figure 2. Two-piece peaked hat.

(Wupu Cemetery, Hami)

\subsubsection{Pointed-Peak Earflap Hats}

Peaked Earflap Hats are mainly seen in the Lop Nor Area. For example, hats have been unearthed from Gumugou Cemetery (Binghua, 2001, p. 31), the Qum-Darya Grave36 (Bergman, 1939, p. 137) and Wupu Cemetery (Xiaobing, 1995, p. 54). They can be divided into two categories in terms of structure: one-piece peaked hats and two-piece peaked hats. The former are more common, similar to fully-fitted felting, with no seams on their surface. These hats are often decorated by wool threads, feathers and weasel skin (Figure 1). Only one two-piece peak hat is unearthed from Wupu, which is sewed by two similar pieces of diamond-shaped woolen cloths, with irregular felt chips seamed in the structure line as special decorations. (Figure 2).

\subsubsection{Dome-Peaked Earflap Hats}

Dome-peaked earflap hats are seamed by two pieces of rectangle cloths, usually with one rounded corner on each piece. The peaks fit the arcs of the wearers' heads, giving a great warmth-keeping practical function. They are more unearthed in the graves of the later period, e.g. in the graves in Zhagunluke Cemetery in Qiemo County and Yanghai (Figure 3) and Subeixi Cemetery in Turfan area (Figure 4).

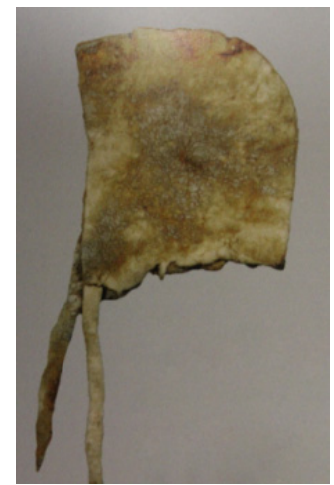

Figure 3. Dome peaked earflap hat.

(Zhagunluke Cemetery, Qiemo)

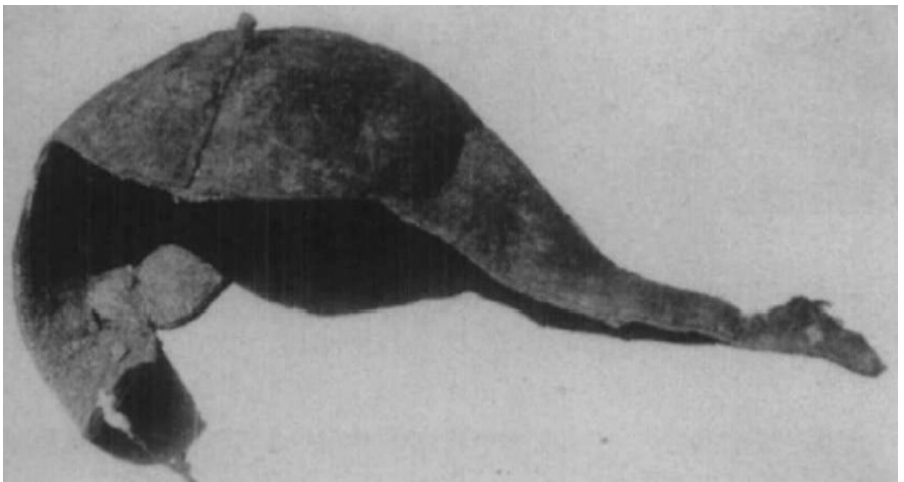

Figure 4. Dome peaked earflap hat.

(Subeixi Cemetery, Shanshan )

\subsubsection{Helmet-Shaped Earflap Hat}

There is a kind of helmet-shaped earflap hat found in prehistoric Xinjiang, which has only been unearthed from Subeixi cemetery in Shanshan County (Binghua, 2001, p. 102), and is sewed by two light-brown felt materials with two earflaps and a crosswise overlapped edge with a width of $1.5 \mathrm{~cm}$. In the middle of the brim, there is a wooden button with three lines of horizontal decoration across the abutted seam to compose a highlighted decorative effect. A few pleat seams are placed on both sides of the brim for fitting. This hat shall be based on a dome-peaked earflap hat, added by a crosswise overlapped edge to form this helmet-shaped earflap hat (Figure $5)$. 

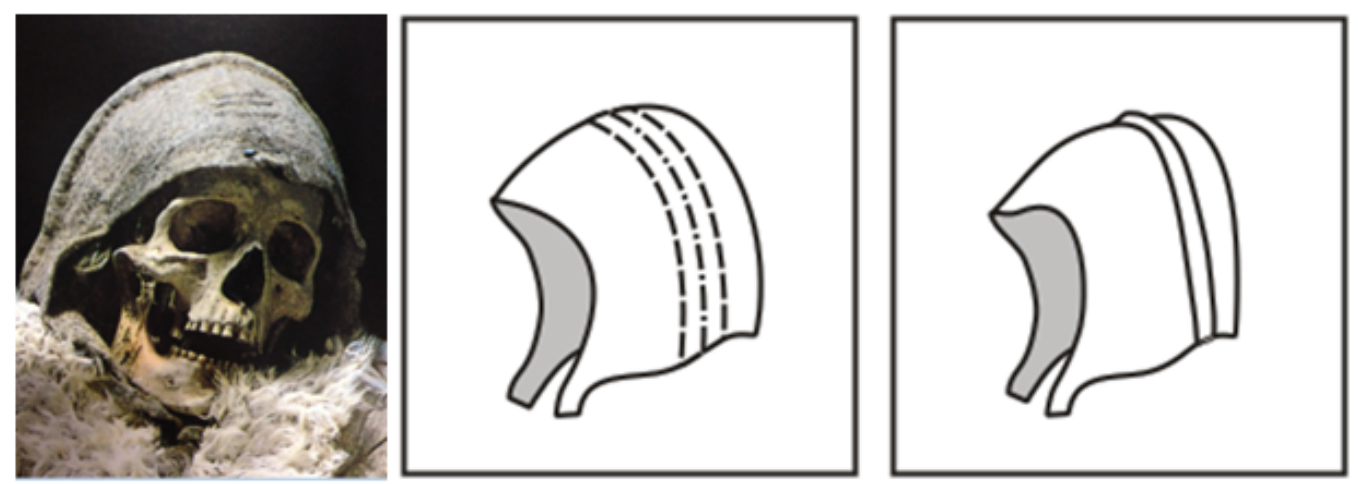

Figure 5. Helmet-shaped earflap hat (Subeixi Cemetery, Shanshan)

\subsection{Straight-Edge Hats}

Straight-edge hats are characterized by circular bottom edges at the same horizontal plane, without earflaps. They can also be divided into three categories: pointed-peak straight-edge hats, dome-peak straight-edge hats and flat-peak straight-edge hats.

\subsubsection{Pointed-Peak Straight-Edge Hats}

Pointed-peak hats feature a pyramid shape, with two kinds - upright pointed-peaks and curved pointed-peaks.

\subsubsection{Upright Pointed-Peak Hats}

Upright pointed-peak hats can be represented by the felt hats unearthed from Small River Cemetery in the Lop Nor Area, which are basically straight-edge round hats without earflaps, with peaks in different pointed degrees. Most hats are well preserved with exquisite modeling (Figure 6). They are as high as $16-35 \mathrm{~cm}$, with bottom diameters of 15-24 cm. Chin cords are also stitched at the two sides of the bottoms for fastening around wearers' jaws. And the surfaces of the hats are often decorated by red, yellow or other colorful wool threads seamed horizontally, along with weasel skin seamed in the middle of the front, or feathers inserted on the left (Xinjiang Institute of Archeology and Culture Relics [XIACR], 2007, p. 10). Characters wearing similar pointed-peak hats are portrayed in a huge number of cliff paintings found in Xinjiang (Figure 7), such as hunter figures in Bostan Ranch cliff paintings in County Mulei (Beihai, 1994, pp. 211-218)

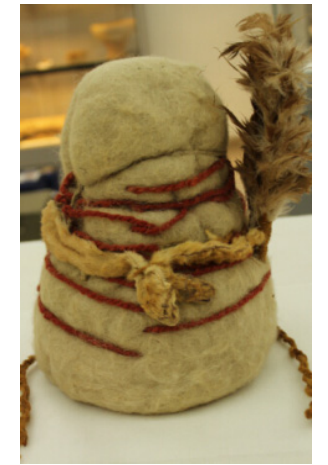

Figure 6. Upright pointed-peak hat

(Small River Cemetery, Ruoqiang)

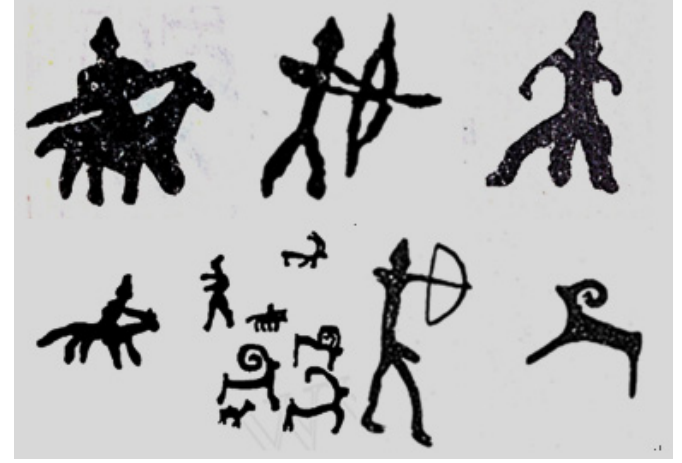

Figure 7. Characters wearing upright pointed-peak hats

(Cliff paintings from Bostan Ranch Petrograms)

\subsubsection{Curved Pointed-Peak Hats}

The peaks of curved pointed-peak hats are not inclined vertically, but have forward or backward folds, which form special curvatures. Only the bird-head-shaped pointed-peak hat unearthed from Zhagunluke is a genuine artifact (Figure 8). It is seamed by two pieces of triangular brown felt materials, small at the top and wide at the bottom; the peak is seamed into the natural curve of a bird head. It is as high as $35 \mathrm{~cm}$, with a bottom diameter of $24 \mathrm{~cm}$ and a top diameter of $5 \mathrm{~cm}$. Its edge is whip-stitched by raw white woolen yarns. A slope shape is formed 
from hat brim to hat peak. It was even inlayed with black feathers when being unearthed. The turn-down brims on both sides are asymmetric, i.e. the right one is turned down in the front and the left one is turned down at the back; two turn-down brims in tandem with the edge in the middle of the hat peak forms a special decorative effect (Museum of Xinjiang Uygur Autonomous Region [MXUAR], 2010, p. 19).

Birds and other animals acted as the spiritual indicators for ancient inhabitants. This kind of bird-head-shape curved pointed hats may be correlated with the religions and nomadic lifestyles of the inhabitants of ancient Xinjiang. Those hats are very rare in graves in prehistoric Xinjiang. However, the hat decorations of the bronze armor sculpture from Yili (Xinyuan County) and the jade sculpture from Altai (Figure 9) are similar with the Zhagunluke Birdhead-shaped Felt Hat. They also have horizontal bottoms and forward-curved peaks (or backward-curved, depending on different styles of use) with different brim widths, showing that these curve-pointed peak straight-edge hats were once popular in prehistoric Xinjiang.

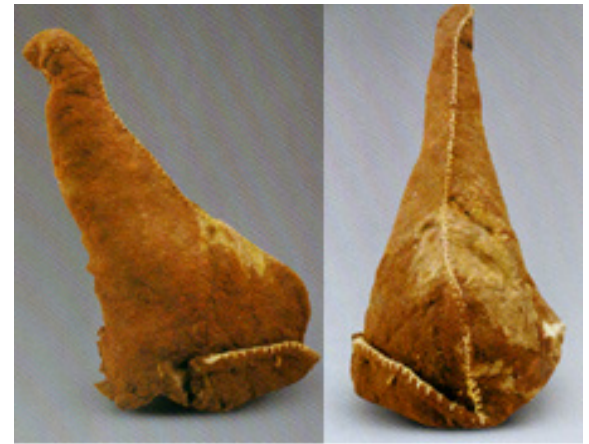

Figure 8. Bird-head-shaped pointed-peak hat (Zhagunluke Cemetery, Qiemo)

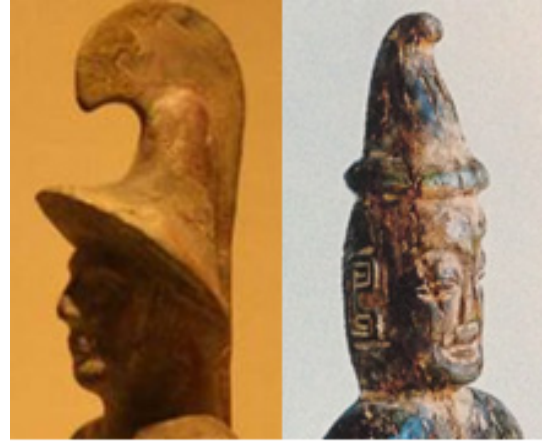

Figure 9. Sculptures with curved pointed-peak hats (Xinyuan, Yili \& Altai)

\subsubsection{Dome-Peaked Straight-Edge Hats}

There are also dome-peaked straight-edge hats unearthed from Xinjiang, the amount of which is far fewer than the pointed-peaked ones. They have a wider shape, with similar top and bottom diameters. The peak lines are naturally round vertically, with the peak profiles in a curve. Felt hats of this kind feature smooth surfaces without well-marked seamed hat ridges, seemingly made of one-piece felts. Take the one unearthed from Small River Cemetery as an example (Figure 10). It is made of raw white felt, with a height of $27 \mathrm{~cm}$, a bottom diameter of $22 \mathrm{~cm}$ and a bottom perimeter of $69 \mathrm{~cm}$. It has a round and smooth peak; the surface is seamed with yellow wool threads and feathers are inserted on the left and weasel skin is seamed in the middle of the front. Five wood figures have been unearthed from Gumugou Tomb, not far from Small River Cemetery, one of which wears the similar dome-peaked round hat (Xinjiang Bureau of Cultural Relics [XBCR], 1997, p. 29) (Figure 11). Despite the lack of material relics, based on the similarity of this burial culture to Small River Cemetery we can infer that these kinds of dome-peaked straight-edge round hats should have been a common style of hat in prehistoric Lop Nor.

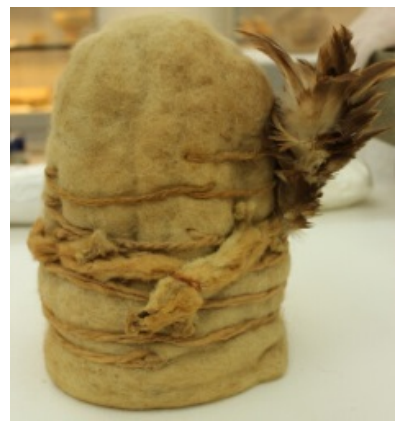

Figure 10. Dome-peaked straight-edge hat

(Small River Cemetery, Ruoqiang)

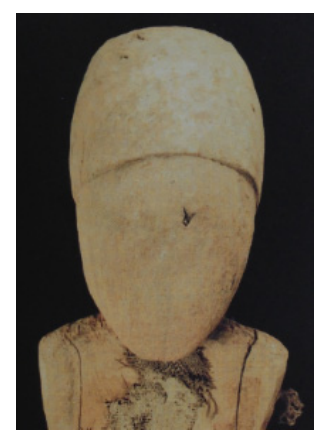

Figure 11. Wood figures with dome-peaked hat (Gumugou Cemetery) 


\subsubsection{Flat-Peaked Straight-Edge Hats}

Flat-peaked straight-edge hats have also been found in prehistoric Xinjiang. There are only two pieces that have been unearthed and both are from Zhagunluke. One is seamed by brown felt in a round shape, with a flat peak with no brim, having a similar shape to the French beret. It is about $25 \mathrm{~cm}$ in diameter and $8 \mathrm{~cm}$ in height. It was made of a striped cloth to form a ring, seamed with a round flat piece for the peak (Bayingolin Prefecture Historic Relic Administration, 1992, pp. 9-10) (Figure 12). Another one is a four-piece brown wool knitting hat, as high as $6.3 \mathrm{~cm}$. It is in an oblate shape, with a small opening and big body (Figure 13). The opening diameter is $18 \mathrm{~cm}$ and the biggest diameter is $30 \mathrm{~cm}$. It is seamed by four brown wool knitted pieces in a fan shape, and the top of each piece is aligned to be seamed (MXUAR, 2010, p. 20). It is notable that the brown felt body in this wool knitted hat is broken, showing that this hat is put on a flat-peaked felt hat. The hat shape demonstrates that its internal hat body and the above-mentioned flat-peaked felt hat share a similar structure, namely it is composed of a round piece of felt for the hat peak and a striped piece of felt for the ring shape.

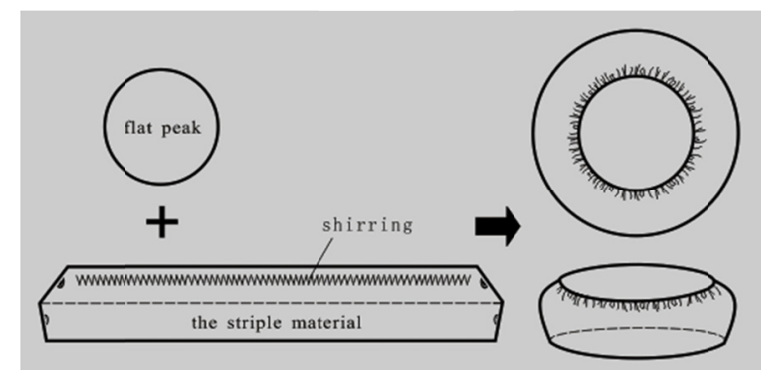

Figure 12. Flat-peaked straight-edge hat

(Zhagunluke Cemetery, Qiemo)

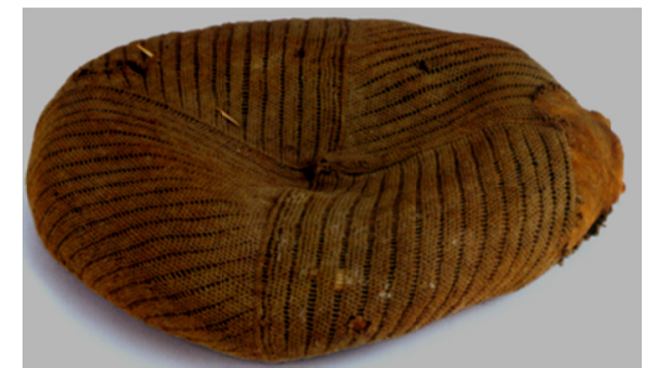

Figure 13. Four-piece brown wool knitting hat

(Zhagunluke Cemetery, Qiemo)

\subsection{High-Peak Hats}

There are high-peak hats, made of felt, wool knitting or wood, unearthed from Xinjiang, which are much higher than ordinary ones, up to $65 \mathrm{~cm}$. Similar high-peak hats have been unearthed from Turfan Basin, such as the graveyards of Subeixi, Yanghai and Sangeqiao. But those hats unearthed from different graveyards are different in structures and textures, with distinct geographic characters, and can be divided, according to their geographic locations, into cone-shaped high-peaked hats, fish-shaped high-peaked hats and double-forked high-peak hats.

\subsubsection{Cone-Shaped High-Peaked Hats}

Cone-shaped high-peaked hats are mainly unearthed from Subeixi Cemetery. Take the high-peaked hat worn by a female corpse unearthed from Graveyard III Tomb 6 as an example (Figure 14). This hat is composed of a base and a cone-shaped peak. Firstly, the black felt is rolled into an ox horn shape to be worn on the wearer's head, and the felt roll is used as a roller to wind the wearer's hair around, which is then covered by a black wool knitted hairnet, to form a round base with a diameter of $24 \mathrm{~cm}$. Then a tapering felt stick shall be put in the middle of the base as high as $45 \mathrm{~cm}$, with a bottom diameter of $8 \mathrm{~cm}$ and an upper diameter of $4 \mathrm{~cm}$, covered by a black hairnet (Binghua, 2001, p. 99). The entire crown decoration has a high-peaked structure that uses felt to support the inside and a knitted hairnet for fastening outside.

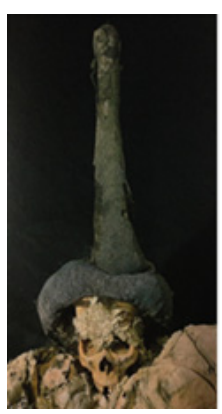

Figure 14. Cone-shaped high-peaked hat (Subeixi Cemetery, Shanshan)

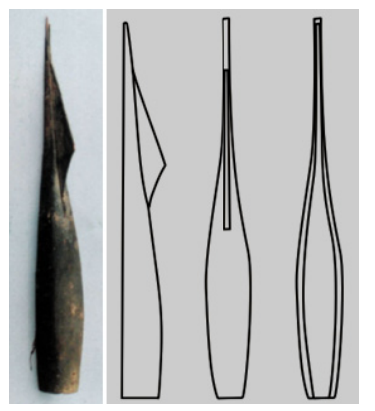

Figure 15. Fish-shaped high-peaked hat (Yanghai Cemetery, Shanshan) 


\subsubsection{Fish-Shaped High-Peaked Hats}

Fish-shaped high-peaked hats have only been unearthed from Yanghai Cemetery. They are wooden hats in a fish shape, bonded by thin wooden boards. The bottom opening is in a square shape. The hat has four facets, with one straight facet as the opening and the other three ones in a fish belly shape, characterized by the swelling bottom and smaller top. The hat peak is stretched upward into a high peak. The slope facet opposite the straight one is fixed with a triangular thin wooden board (Figure 15). These hats, usually utilized by females, are of a similar structure but different heights. All hats were blackened and in the form of empty shells when being unearthed. A well-preserved example among these wooden hat decorations is the M318:16, which is as high as 62.4 centimeters, with an opening length of $5.2 \mathrm{~cm}$. When being unearthed, its shell was inserted with a square wooden strip, 26 centimeters in length and 1.2 centimeters in width; there are woolen ropes wound around the peak with human hairs inside (XIACR \& Turfan Bureau of Cultural Relics, 2004, pp. 61-62). This stripe should be the holder to support the wearer's hair when using this fish-shaped decoration. And it is inferred that there is also a hairnet or internal hat in the bottom to support the high peak at the same time.

\subsubsection{Double-Forked High-Peaked Hats}

The peak of a double-forked high-peaked hat is bifurcated into two forks. Among five unearthed ones, two were from Subeixi and 3 were from Sangeqiao, with similar structures and different characteristics.

The double-forked high-peaked hats unearthed from Subeixi Cemetery shall be represented by the one worn by a female corpse from Graveyard I Tomb 11 (Figure 16). The wearer's hair is braided into two parts, which are covered by a black wool knitted hairnet to be wound on her head and supported by a wooden hairpin. A tower-shaped double-forked felt hat is worn on top of the wound hair. It is in a barrel shape, as high as $45 \mathrm{~cm}$, seamed by a piece of black fine felt. The seam is concave and decorated with fur. The peak is formed into two forks, inserted by a wooden stripe. A fur ring-like base is connected below the felt top, decorated by evenly spaced fine white vertical stripes. A leather rope is seamed at the center, front, left and right of the hat brim. The leather rope end in the center front is tied with a wooden hairpin, and the other two ropes are tied behind the wearer's head (Enguo, 2006, p. 245). To wear this hat, the wearer shall wind her hair, which is braided into two parts on top of her head and covered by the knitted hairnet, and fasten the ring-like base around her neck; and finally cover the top of her head with a double-forked high peak.

Three similar pieces of double-formed high-peaked hats have been unearthed from Sangeqiao Cemetery, close to Subeixi. For instance, let's look at the M9:10 (Figure 17). Firstly, one piece of felt is seamed into a barrel shape, with a lower front and higher back. The back is seamed smoothly, with the upper part cut into two peaks in the shape of horse ears. The hat is as high as $27 \mathrm{~cm}$, with a bottom diameter of $6.2 \mathrm{~cm}$. The bottom part of the back is tied with fur stripes for fastening. The high-peaked hat M13:3 shares a similar shape with the former one, but it is seamed by two pieces of overlapped felt, with seam traces in the front and back of the center lines. But a half circle is cut in the front part, and a fur stripe is tied below for fastening. The incomplete hat is as high as $24.2 \mathrm{~cm}$, with a bottom diameter of $7.4 \mathrm{~cm}$ (XIACR et al., 1997, p. 15)

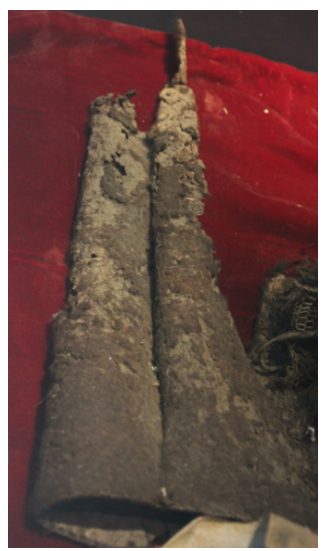

Figure 16. double-forked high-peaked hat

(Subeixi Cemetery, Shanshan)

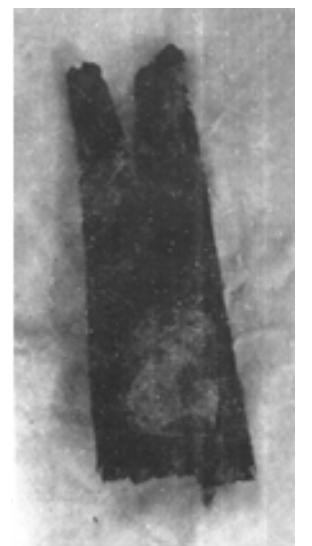

Figure 17. double-forked high-peaked hat

( Sangeqiao Cemetery, Shanshan) 


\section{Discussions}

This is a preliminary classification and consolidation of hat styles in prehistoric Xinjiang, which can be divided into earflap hats, straight-edged hats and high-peaked hats. The first two kinds of hat were utilized prior to the high-peaked ones, and are very common among garment relics, while high-peaked hats were mostly distributed in the Tianshan Mountain area of Eastern Xinjiang in 5-3 centuries BC, and were a unique style of hat in the prehistoric Turfan Basin. From a chronological perspective, most early hats in 2000-1300 BC are unearthed from the Lop Nor Area, and were used for practical functions, featuring simple and plain styles, textures and colors. While mid-period hats from 1300-600 BC, represented by the hats of the Zhaguanluke area feature complicated styles and diverse textures, with a texture composed of a mixture of felt, woolen cloth and knitted cloth. Hats from $600 \mathrm{BC}$ to the Han Dynasty, beginning in $206 \mathrm{AD}$, were mainly unearthed from the Turfan Basin. High-peaked hats have become the main characteristic of this area. These hats feature three different types, which function as unique spiritual indicators: cone-shape, fish shape and double-fork shape.

Peak shape and style has become an important feature of hats in prehistoric Xinjiang, and can be a symbol of certain ethnic or religious groups. The excavated felt hats have shown the limitations of the excessive focus on high-peaked hats by the academic field when referring to the hat history of Western China. Despite high-peaked hats taking up a great portion of all the hats in prehistoric Xinjiang, there are also dome-peaked, round-peaked and flat-peaked hats, as well as hats with special animal shapes. Dome-shaped earflap hats had the longest period of popularity as well as the widest distribution and have been unearthed from multiple graves, showing that this style of hat was commonly used in ancient times. Pointed hats featured more surface decorations with straight or curved top styles and uneven heights, which were more likely utilized on formal occasions. High-peaked hats were seemingly used for special ceremonies and religious rituals or as coffin decorations, rather than for daily use.

These three categories of hats in prehistoric Xinjiang, from the Bronze Age to the early Iron Age, were unearthed from other places in Eurasia. For instance, the statue of Phoenicia Prayer from 4000-3500 BC unearthed from Byblos, Lebanon, wears a straight-edge hat with a peak point, while there is also a tribute bearer wearing a straight-edged hat in the Assyrian civilization 2800 years ago. The earflap hats often appeared later in the Persian and Scythian Nomadic Civilizations, such as the Scythian tribute bearers in the embossment in Persepolis Palace built by Darius 2500 years ago, and the Scythian warriors portrayed on the golden vase, unearthed from Kul-Oba Ancient Tomb in South Russia, wearing earflap pointed hats. The high-peaked hats also appeared in Central Asia and the South Russian grasslands in 6-3 centuries BC, such as the gold man unearthed from a grave in Issyk in 5 century BC in Kazakhstan, wearing a bird-shaped high-peak hat; or the female corpse unearthed from Pazyryk ancient tomb in South Siberia, Russia, wearing a cone-shaped high-peaked hat, similar to the ones unearthed in Subeixi Ancient Tomb in Xinjiang. These similarities seemingly suggest that from as early as $2000 \mathrm{BC}$ to the Christian era, there were initial cultural exchanges in Eurasia, and more archaeological evidence is needed in order to fully unveil their origins and ways in which they spread around Eurasia.

\section{Summary}

These observations about hats unearthed from prehistoric Xinjiang may certainly expand our knowledge of the Bronze and Early Iron Age dwellers of Xinjiang, although some other important aspects need to be explored through further research.

\section{Acknowledgments}

It is a project supported by the Top-Class Academic Discipline Project of Shanghai (Type B).

\section{References}

Barber, E. W. (1999). The mummies of ürümchi. New York, London: W. W. Norton.

Bayingolin Prefecture Historic Relic Administration. (1992). A breif report of Zhagunluke ancient cemetery, Qiemo in 1989. Cultural Relics of Xinjiang, 2, 9-10.

Beihai, S. (1994). Cliff paintings of Xinjiang. Urumqi: Xinjiang Art \& Photography Press.

Bergman, F. (1939). Archaeological researches in Xinjiang: The Sino-Swedish expedition publication 7. Stockholm: Bokförlags Aktiebolaget Thule.

Binghua, W. (2001). The Ancient corpses of Xinjiang: The peoples of ancient Xinjiang and their culture. Urumqi: Xinjiang People's Press.

Enguo, L. (2006). The chief accomplishment of excavaion of Subeixi cemetery. In Y. Qing (Ed.), The New Theory of Turfanology (pp. 239-252). Urumqi: Xinjiang People's Press. 
Institute of Cultural Relics and Archeology of Xinjiang. (2007). A brief excavation report on Xiaohe graveyard Located in Luobupo, Xinjiang Autonomous Region. Cultural Relics, 10, 4-42.

Karlene J, (2010). Tall hats: Reaching to the sky. In A. Turfanica (Ed.), Journal of the Turfan Studies (pp. 92-98). Shanghai: Shanghai Ancient Book Press.

Museum of Xinjiang Uygur Autonomous Region. (2010). Costume essence in ancient western regions. Beijing: Cultural Relics Press.

Xiaobing, L. (1995). Costume of ethnic groups in the western region of China. Urumqi: Xinjiang People's Press.

Xinjiang Bureau of Cultural Relics. (1997). A grand view of Xinjiang's cultural relics and historic sites. Urumqi: Xinjiang Art \& Photography Press.

Xinjiang Institute of Archeology and Culture Relics \& Turfan Bureau of Cultural Relics. (2004). A brief excavation report on Yanghai graveyard III of Shanshan county. Cultural Relics of Xinjiang, 1, 61-62.

Xinjiang Institute of Archeology and Culture Relics, 1988 Archeology Major of Department of History in Xinjiang University, Museum of Turfan Prefecture, \& Shanshan Bureau of Cultural Relics. (1997). The salvage excavation of Sangeqiao ancient cemetery in Shanshan, Xinjiang. Cultural Relics of Xinjiang, 2, $1-21$.

Yanchun, W., \& Libo, W. (2004). The high-peaked headgear culture of the West Region. The Western Regions Studies, 1, 60-68.

\section{Copyrights}

Copyright for this article is retained by the author(s), with first publication rights granted to the journal.

This is an open-access article distributed under the terms and conditions of the Creative Commons Attribution license (http://creativecommons.org/licenses/by/3.0/). 